\title{
Hubungan Sistem Pengendalian Internal dan Gaya Kepemimpinan Terhadap Kinerja Karyawan di Swan Keramas Bali
}

\author{
Ni Luh Putu Mita Miati", I Nyoman Sutapa, Putu Gede Wisnu Permana Kawisana \\ Fakultas Ekonomi dan Bisnis, Program Studi Akuntansi, Universitas Warmadewa, Denpasar, Indonesia \\ Email: 1," mitamiati91@gmail.com, ${ }^{2}$ sutapanym@gmail.com, ${ }^{3}$ permanaunwar@gmail.com \\ Email Penulis Korespondensi: mitamiati91@gmail.com \\ Submitted: 06/11/2021; Accepted: 12/11/2021; Published: 30/11/2021
}

\begin{abstract}
Abstrak-Karyawan memegang peranan penting dalam menjalankan segala aktivitas perusahaan agar dapat tumbuh berkembang mempertahankan kelangsungan hidup perusahaan. Untuk menciptakan sumber daya manusia yang handal membutuhkan pengelolaan yang baik agar Kinerja Karyawan lebih optimal. Pengendalian Internal dan Gaya kepemimpinan yang efektif dibutuhkan dalam suatu organisasi perusahaan untuk dapat meningkatkan kinerja semua karyawan dalam mencapai tujuan yang telah ditetapkan perusahaan. Desain penelitian yang digunakan dalam penelitian ini adalah metode survei. Populasi pada penelitian ini adalah seluruh karya wan di Swan Keramas Villas Bali yang berjumlah 51 karyawan. Untuk dapat lebih menggeneralisasi maka sampel Pada penelitian ini menggunakan sampel jenuh. Dari hasil penelitian didapatkan hasil Sistem Pengendalian Internal berpengaruh positif terhadap kinerja karyawan dan Gaya kepemimpinan berpengaruh positif terhadap kinerja karyawan. Pada penelitian ini memiliki nilai R Square sebesar 0,696 maka, untuk penelitian selanjutnya disarankan memperbanyak sampel dan menambahkan beberapa variabel.
\end{abstract}

\section{Kata Kunci: Sistem pengendalian Internal; Gaya Kepemimpinan; Kinerja Karyawan; Swan Keramas Bali}

\begin{abstract}
Employees play an important role in carrying out all company activities in order to grow to maintain the survival of the company. To create reliable human resources requires good management so that employee performance is more optimal. Internal Control and Effective leadership style are needed in a company organization to be able to improve the performance of all employees in achieving the goals set by the company. The research design used in this study is a survey method. The population in this study was all employees at Swan Keramas Villas Bali which amounted to 51 employees. To be able to better generalize then the sample in this study uses saturated samples. From the results of the study, the results of the Internal Control Sy stem have a positive effect on employee performance and leadership style has a positive effect on employee performance. In this study has a value of R Square of 0.696 then, for further research it is recommended to multiply the sample and add some variables.
\end{abstract}

Keywords: Internal Control System; Leadership Style; Employee Performance; Swan Keramas Bali

\section{PENDAHULUAN}

Kinerja merupakan suatu fungsi kemampuan pekerja dalam menerima tujuan pekerjaan, tingkat pencapaian tujuan dan interaksi antara tujuan dan kemampuan pekerja menurut Judith R. Gordon dalam Nawawi (2006: 63). Dengan definisi tersebut dapat dikatakan bahwa karyawan memegang peranan penting dalam menjalankan segala aktivitas perusahaan agar dapat tumbuh berkembang mempertahankan kelangsungan hidup perusahaan. Untuk menciptakan sumber daya manusia yang handal membutuhkan pengelolaan yang baik agar Kinerja Karyawan lebih optimal. Pencapaian tujuan perusahaan dipengaruhi oleh Kinerja Karyawan perusahaan itu sendiri. Maka dari itu perusahaan membutuhkan sumber daya manusia yang berpotensial dan berkualitas, baik dari segi pemimpin maupun karyawan pada pola tugas, tanggung jawab, berdaya guna sesuai dengan peraturan dan pengawasan yang merupakan penentu tercapainya tujuan perusahaan.

Suatu perusahan yang telah berjalan sebaiknya memantau seluruh kegiatan operasionalnya. Sebuah pengendalian digunakan untuk membantu memantau kegiatan-kegiatan perusahaan. AICPA (American Institute of Certified Public accountants) dalam Muhammad (2017) menjelaskan bahwa pengendalian internal sangat penting, antara lain untuk memberikan perlindungan bagi entitas terhadap kelemahan manusia serta untuk mengurangi kemungkinan kesalahan dan tindakan yang tidak sesuai dengan aturan. Pengelolaan dan penerapan pengendalian internal yang baik maka suatu perusahaan akan lebih mudah dalam pencapaian tujuannya.

Kinerja Karyawan dapat mengalami penurunan, hal seperti ini dapat terjadi dikarenakan adanya motivasi kerja di dalam diri mereka menurun dan adanya peluang-peluang untuk melakukan kecurangan. Pengimplementasian Pengendalian Internal yang baik pada semua struktur organisasi dalam perusahaan, maka dapat disediakan jaminan memadai mengenai prestasi dari sasaran kinerja dalam mengefektivitas dan mengefisiensikan operasional perusahaan, sehingga dalam laporan keuangan dapat memenuhi ketentuan hukum yang bisa diterapkan dan diregulasi. Jika Pengendalian Internal lemah maka akan mengakibatkan kekayaan perusahaan tidak terjamin keamanannya, informasi akuntansi yang ada tidak teliti dan tidak dapat dipercaya kebenarannya, tidak efisien dan efektifnya kegiatan-kegiatan operasional perusahaan serta tidak dapat dipatuhinya kebijakan yang telah ditetapkan.

Upaya-upaya dalam meningkatkan Kinerja Karyawan selain Pengendalian Internal, Gaya Kepemimpinan juga perlu diperhatikan. Seorang pemimpin yang ideal harus memiliki Gaya Kepemimpinan yang baik sehingga dapat meningkatkan kinerja karyawannya. Flippo (1994) dalam Nurjanah (2008: 39) berpendapat gaya kepemimpinan dapat dirumuskan sebagai suatu pola perilaku yang dirancang untuk memadukan kepentingan kepentingan organisasi dan personalia guna mengejar beberapa sasaran. Gaya Kepemimpinan seorang pemimpin sangat diperlukan dalam suatu organisasi karena maju mundurnya suatu organisasi tergantung seberapa baik pemimpin dapat memainkan perannya agar organisasi tersebut terus hidup dan berkembang. Untuk itu seorang pemimpin sangat perlu memperhatikan gaya 
kepemimpinannya dalam proses mempengaruhi, mengarahkan kegiatan anggota kelompoknya serta mengkoordinasikan tujuan anggota dan tujuan organisasi agar keduanya dapat tercapai.

Gaya kepemimpinan yang baik adalah gaya kepemimpinan yang dapat memberikan motivasi kerja pada bawahannya. Ivancevich (2001) dalam Widyatmini dan Hakim (2011) mengatakan seorang pemimpin harus menyatukan berbagai keahlian, pengalaman, kepribadian dan motivasi setiap individu yang dipimpinnya. Karyawan dapat memandang pimpinannya sebagai pemimpin yang efektif atau tidak, berdasarkan kepuasan yang mereka peroleh dari pengalaman kerja secara keseluruhan, sehingga diterimanya arahan atau permintaan pemimpin sebagian besar tergantung pada harapan pengikutnya (Rachmawati, 2004:68). Kinerja karyawan akan baik apabila pimpinan dapat memberi motivasi yang tepat dan pimpinan memiliki gaya kepemimpinan yang dapat diterima oleh seluruh karyawan dan mendukung terciptanya suasana kerja yang baik. Gaya kepemimpinan yang tidak efektif tidak akan memberikan pengarahan yang baik pada bawahannya terhadap usaha-usaha semua pekerjaan dalam mencapai tujuan-tujuan organisasi dalam perusahaan.

Pengendalian Internal dan Gaya kepemimpinan yang efektif dibutuhkan dalam suatu organisasi perusahaan untuk dapat meningkatkan kinerja semua karyawan dalam mencapai tujuan yang telah ditetapkan perusahaan. Berdasarkan latar belakang tersebut, maka mendorong penulis untuk melakukan penelitian dengan judul Hubungan Sistem Pengendalian Internal Dan Gaya Kepemimpinan Terhadap Kinerja Karyawan Di Swan Keramas Villas Bali. Berdasarkan uraian pada latar belakang permasalahan, maka penelitian memiliki tujuan khusus untuk mengetahui pengaruh Sistem Pengendalian Internal (SPI) berpengaruh terhadap Kinerja Karyawan dan Mengetahui pengaruh Gaya Kepemimpinan berpengaruh terhadap kinerja karyawan.

Pengendalian Internal adalah segala sesuatu meliputi struktur organisasi, semua metode dan alat-alat yang dikoordinasikan yang digunakan dalam perusahaan dengan tujuan menjaga keamanan harta milik perusahaan, memeriksa ketelitian dan kebenaran data akuntansi, mendorong efisiensi, dan membantu mendorong dipatuhinya kebijakan manajemen yang telah ditetapkan. Komponen komponen dalam Pengendalian Internal seperti lingkungan pengendalian yang baik, akan memberikan kontribusi baik dalam menciptakan suasana kerja sehingga dapat mendorong karyawan untuk meningkatkan kinerjanya. Aktivitas pengendalian akan mendorong karyawan menaati dan melaksanakan peraturan dan standar kerja yang sudah ditetapkan. Pemantauan yang baik akan membuat karyawan untuk lebih disiplin dalam bekerja. Berdasarkan hal tersebut maka dapat dirumuskan $\mathrm{H}^{1}$ : Pengendalian Internal berpengaruh positif terhadap Kinerja Karyawan

Kinerja Karyawan juga dapat dipengaruhi oleh Gaya kepemimpinan yang dianut dan diterapkan oleh manajemen puncak atau pimpinan. Teori path Goal mengansumsikan bahwa pimpinan bisa mengubah gaya atau perilaku mereka untuk memenuhi permintaan dari situasi tertentu, misalnya saat menghadapi kelompok bawahan baru atau proyek baru, pemimpin mungkin berprilaku direktif dalam membuat prosedur kerja dan menjelaskan apa yang mesti dilakukan. Berikutnya, pemimpin dapat menggunakan perilaku suportif untuk meningkatkan kepaduan kelompok dan menumbuhkan iklim positif. Setelah kelompok familier dengan tugas dan saat masalah-masalah baru ditemukan, pemimpin dapat menampakkan perilaku partisipatif untuk meningkatkan motivasi anggota kelompok. Terakhir, perilaku yang berorientasi pada prestasi dapat dipakai untuk mendorong kinerja yang semakin meningkat. Penerapan Gaya Kepemimpinan yang sesuai dengan karakter karyawan, pekerjaan, dan kondisi yang ada dapat memberikan kontribusi terhadap peningkatan Kinerja Karyawan. Berdasarkan hal tersebut maka dapat dirumuskan $\mathrm{H}^{2}$ : Gaya Kepemimpinan berpengaruh positif terhadap kinerja karyawan.

Hasil dari penelitian ini diharapkan dapat dijadikan bahan dasar untuk pengabdian masyarakat dibidang akuntansi yang berjudul pelatihan perancangan sistem pengendalian internal yang baik untuk meningkatkan kinerja karyawan dan membuka peluang bagi disusunya buku ajar tentang Sistem pengendalian internal dan gaya kepemimpinan dalam meningkatkan kinerja karyawan.

\section{METODE PENELITIAN}

Desain penelitian yang digunakan dalam penelitian ini adalah metode survei. Desain penelitian survei merupakan suatu perancangan penelitian dengan tujuan melakukan pengujian yang cermat dan teliti terhadap suatu obyek penelitian berdasarkan suatu situasi atau kondisi tertentu dengan melihat kesesuaiannya dengan pernyataan atau nilai tertentu yang diikuti dan diamati dengan cermat dan teliti (Saputra, 2014). Penelitian akan dilakukan dengan cara survei terhadap pegawai swan keramas villas Bali.

Populasi pada penelitian ini adalah seluruh karyawan di Swan Keramas Villas Bali yang berjumlah 51 karyawan. Untuk dapat lebih menggeneralisasi maka sampel Pada penelitian ini menggunakan sampel jenuh. Metode pengumpulan data dalam penelitian ini yaitu dengan teknik pengumpulan kuesioner.

Teknik analisis pada penelitian ini menggunakan Partial Least Square (PLS) dengan terlebih dahulu Asesmen Model Pengukuran (Outer Model) dan Asesmen Model Struktural (Inner Model). Pengujian hipotesis diuji dengan melihat nilai $p$ value dengan ketentuan sebagai berikut; Hipotesis alternatif diterima jika $p$ value $<0,05$. 


\subsection{Asesmen Model Pengukuran (Outer Model)}

Berdasarkan hasil olah data dengan menggunakan sofeware smart PLS dapat dilihat pada tabel 1 nilai Cronbach's Alpha diatas nilai minimal yaitu 0,7 maka dapat disimpulkan bahwa data pada penelitian ini sudah reliabel. Nilai square root of average variance extracted (AVE) pada tabel 1 menunjukan nilai diatas 0,5 . Dapat disimpulkan bahwa semua indikator dalam penelitian ini dinyatakan valid.

Tabel 1. Hasil Uji Instrumen

\begin{tabular}{lllll}
\hline \multicolumn{1}{c}{ Variabel } & Item & $\begin{array}{c}\text { Cronbac } \\
\text { h's Alpha }\end{array}$ & (AVE) & Ket \\
\hline Sistem Pengendalian Internal (X1) & 13 & 0,919 & 0,510 & Valid \& Reliabel \\
\hline Gaya Kepemimpinan (X2) & 8 & 0,869 & 0,529 & Valid \& Reliabel \\
\hline Kinerja Karyawan (Y) & 13 & 0,958 & 0,671 & Valid \& Reliabel \\
\hline Sumber : data diolah Smart PLS, 2020 & & &
\end{tabular}

Sumber : data diolah, Smart PLS, 2020

\subsection{Asesmen Model Struktural (Inner Model)}

Berdasarkan hasil olah data pada tabel 2 Asesmen Model Struktural (Inner Model) dapat dilihat relasi atau koefisien jalur antar peubah laten yang satu dengan peubah laten yang lain (Nilai $\beta$ ) dan koefisien determinasi $\left(\mathrm{R}^{2}\right)$ dari setiap peubah laten endogen.

Tabel 2. Asesmen Model Struktural (Inner Model)

\begin{tabular}{|c|c|c|}
\hline Variabel & Nilai $\beta$ & Hipotesis \\
\hline $\begin{array}{l}\text { Sistem Pengendalian Internal } \\
\text { (X1) }\end{array}$ & 0,579 & Sesuai \\
\hline Gaya Kepemimpinan (X2) & 0,305 & Sesuai \\
\hline R Square adjusted & & \\
\hline
\end{tabular}

Sumber : data diolah, Smart PLS, 2020

Pada tabel 2 dilihat dari nilai $\beta$ dapat diartikan Sistem pengendalian internal bernilai positif yaitu sebesar 0,579 dan Gaya kepemimpinan memiliki nilai positif yaitu sebesar 0,305 . Berdasarkan hal tersebut maka hipotesis $\mathrm{H}^{1}$ dan $\mathrm{H}^{2}$ yang diajukan dapat dikatakan sesuai. Nilai $\mathrm{R}^{2}$ sebesar 0,696 ini berarti variabel bebas yaitu Sistem pengendalian internal dan Gaya kepemimpinan mampu menjelaskan variabel terikat kinerja karyawan sebesar 69\%, sedangkan sisanya sebesar $29, \%$ dijelaskan oleh variabel lain.

\subsection{Hasil}

a. Pengaruh Pengendalian Internal Terhadap Kinerja Karyawan

Hasil pengujian pada tabel 3 menunjukan signifikansi sebesar 0.000 lebih kecil dari $\alpha=(0,05)$ dapat diartikan Sistem Pengendalian Internal berpengaruh positif terhadap Kinerja Karyawan. Berdasarkan hal tersebut maka hipotesis pertama diterima atau didukung.

b. Pengaruh Gaya Kepemimpinan terhadap Kinerja Karyawan

Hasil pengujian pada tabel 3 menunjukan signifikansi sebesar 0.020 lebih kecil dari $\alpha=(0,05)$ dapat diartikan Gaya Kepemimpinan berpengaruh terhadap Kinerja Karyawan. Berdasarkan hal tersebut maka hipotesis kedua diterima atau didukung.

Tabel 3. Uji Hipotesis

\begin{tabular}{lcc}
\hline \multicolumn{1}{c}{ Variabel } & B & P value \\
\hline Sistem Pengendalian Internal (X1)-> Penerapan SAK EMKM (Y) & 0,579 & 0,000 \\
\hline Gaya Kepemimpinan (X2) )-> Penerapan SAK EMKM (Y) & 0,305 & 0,020 \\
\hline
\end{tabular}

Sumber : Data diolah 2020

\subsection{Pembahasan}

a. Pengaruh Pengendalian Internal Terhadap Kinerja Karyawan

Berdasarkan hasil penelitian pada tabel 3 disampaikan bahwa pengendalian internal berpengaruh positif terhadap kinerja karyawan. berdasarkan kajian Pustaka Komponen komponen dalam Pengendalian Internal seperti lingkungan pengendalian yang baik, akan memberikan kontribusi baik dalam menciptakan suasana kerja sehingga dapat mendorong karyawan untuk meningkatkan kinerjanya. Aktivitas pengendalian akan mendorong karyawan menaati dan melaksanakan peraturan dan standar kerja yang sudah ditetapkan. Pemantauan yang baik akan membuat karyawan untuk lebih disiplin dalam bekerja. Hasil penelitian ini searah dengan beberapa penelitian yaitu Dewi (2012), Arifiyani (2012), Maharani (2015), Taradipa (2017), Miati (2019).

b. Pengaruh Gaya Kepemimpinan terhadap Kinerja Karyawan 
Berdasarkan hasil penelitian pada tabel 3 disampaikan bahwa Gaya kepemimpinan berpengaruh positif terhadap kinerja karyawan. Berdasarkan kajian Pustaka Teori path Goal mengansumsikan bahwa pimpinan bisa mengubah gaya atau perilaku mereka untuk memenuhi permintaan dari situasi tertentu, misalnya saat menghadapi kelompok bawahan baru atau proyek baru, pemimpin mungkin berprilaku direktif dalam membuat prosedur kerja dan menjelaskan apa yang mesti dilakukan. Berikutnya, pemimpin dapat menggunakan perilaku suportif untuk meningkatkan kepaduan kelompok dan menumbuhkan iklim positif. Setelah kelompok familier dengan tugas dan saat masalah-masalah baru ditemukan, pemimpin dapat menampakkan perilaku partisipatif untuk meningkatkan motivasi anggota kelompok. Terakhir, perilaku yang berorientasi pada prestasi dapat dipakai untuk mendorong kinerja yang semakin meningkat. Penerapan Gaya Kepemimpinan yang sesuai dengan karakter karyawan, pekerjaan, dan kondisi yang ada dapat memberikan kontribusi yang besar terhadap peningkatan Kinerja Karyawan. Hasil penelitian ini searah dengan beberapa penelitian yaitu Dewi (2012), Sumarwinati (2019), Desky (2014), dan Rahmawati (2006)

\section{KESIMPULAN}

Berikut adalah kesimpulan yang dapat peneliti rangkum adalah Sistem Pengendalian Internal berpengaruh positif terhadap kinerja karyawan, dan Gaya kepemimpinan berpengaruh positif terhadap kinerja karyawan. Pada penelitian ini memiliki nilai R Square sebesar 0,696 maka, untuk penelitian selanjutnya masih bisa meningkatkannya lagi dengan memperbanyak sampel dan menambahkan beberapa variabel yang relevan.

\section{UCAPAN TERIMAKASIH}

Terima kasih disampaikan kepada prodi akuntansi Fakultas Ekonomi dan Bisnis Universitas Warmadewa yang telah membantu dalam penyusunan penelitian ini dan kepada responden yang sudah mau memberikan datanya untuk dilakukan penelitian dalam penelitian ini. dan terima kasih kepada Jurnal Ekonomi, Keuangan, Investasi dan Syariah (EKUITAS) sehingga artikel ini bisa terbit dengan tepat waktu.

\section{REFERENCES}

Arifiyani, H. A., \& Sukirno, S. (2012). Pengaruh Pengendalian Intern, Kepatuhan dan Kompensasi Manajemen terhadap Perilaku Etis Karyawan (Studi Kasus PT Adi Satria Abadi Yogyakarta). Nominal: Barometer Riset Akuntansi dan Manajemen, 1(2), 1-21.

Desky, H. (2014). Pengaruh etos kerja islami dan gaya kepemimpinan terhadap kinerja karyawan rumah makan ayam lepaas lhokseumawe. INFERENSI: Jurnal Penelitian Sosial Keagamaan, 8(2), 459-478.

Dewi, S. P. (2012). Pengaruh pengendalian internal dan gaya kepemimpinan terhadap kinerja karyawan SPBU Yogyakarta (studi kasus pada spbu anak cabang perusahaan RB. Group). Nominal: Barometer Riset Akuntansi dan Manajemen, 1(1).

Maharani, F. L., Sofianti, S. P. D., \& Wardayanti, S. M. (2015). Pengaruh pengendalian internal terhadap kinerja karyawan pada divisi pelayanan medis di rumah sakit Jember Klinik. Jurnal Akuntansi Universitas Jember, 13(2).

Miati, N. L. P. M., \& Sutapa, I. N. (2019). Efektivitas Sistem Informasi Akuntansi dan Pengaruhnya Terhadap Kinerja Karyawan Dengan Teknologi Informasi Sebagai Pemoderasi. Jema adpertisi journal, 1(1).

Muhammad, R., \& Ibrahim, R. (2017). Pengaruh Kesesuaian Kompensasi, Penerapan Sistem Informasi Akuntansi, dan Efektivitas Pengendalian Internal Terhadap Kecurangan Akuntansi Studi Pada Bank Perkreditan Rakyat (BPR) di Kota Banda Aceh. Jurnal Ilmiah Mahasiswa Ekonomi Akuntansi, 2(4), 136-145.

Nawawi, H. (2006). Evaluasi dan Manajemen Kinerja di Lingkungan Perusahaan dan Industri. Yogyakarta: UGM Press.

Nurjanah, N. (2008). Pengaruh Gaya Kepemimpinan Dan Budaya Organisasi Terhadap Komitmen Organisasi Dalam Meningkatkan Kinerja Karyawan (Studi Pada Biro Lingkup Departemen Pertanian) (Doctoral dissertation, program Pascasarjana Universitas Diponegoro).

Rahmawati, E., Warella, Y., \& Hidayat, Z. (2006). Pengaruh Motivasi Kerja, Kemampuan Kerja dan Gaya Kepemimpinan Terhadap Kinerja Karyawan Pada Badan Kesatuan Bangsa dan Perlindungan Masyarakat Propinsi Jawa Tengah. Jurnal Ilmu Administrasi dan Kebijakan Publik, 3(1), 89-97.

Santosa, P. I. (2018). Metode penelitian kuantitatif: Pengembangan hipotesis dan pengujiannya menggunakan SmartPLS.

Saputra, K. A. K. (2014). Pengaruh Locus of Control terhadap Kinerja dan Kepuasan Kerja Internal Auditor dengan Kultur Lokal Tri Hita Karana sebagai Variabel Moderasi. Jurnal Akuntansi Multiparadigma, 3(1), 86-100.

Sumarwinati, S., \& Ratnasari, S. L. (2019). Pengaruh Budaya Organisasi, Kepuasan Kerja dan Gaya Kepemimpinan Terhadap Kinerja Karyawan Dengan Komitmen Organisasional Sebagai Variabel Interverning. Jurnal Dimensi, 8(1), 13-27.

Taradipa, P. S. (2017). Pengaruh Pengendalian Intern Terhadap Kinerja Karyawan Studi pada PT Bank Panin TBK Cabang Kendari. Jurnal Akuntansi, 2(1).

Widyatmini, W., \& Hakim, L. (2011). Hubungan kepemimpinan, kompensasi dan kompetensi terhadap kinerja pegawai dinas kesehatan kota depok. Jurnal Ilmiah Ekonomi Bisnis, 13(2). 